\title{
Brotes de sarampión en países desarrollados. Una lección para Chile
}

\author{
Jaime Cerda, Katia Abarca y Jorge Jiménez
}

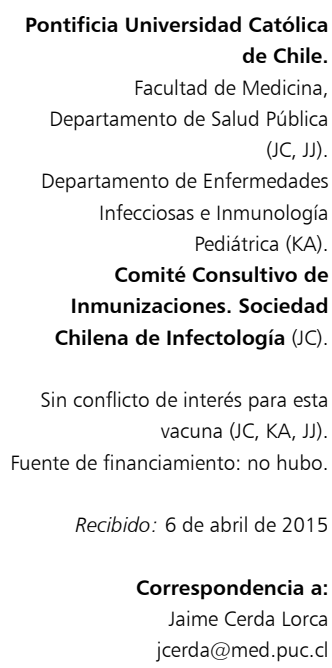

Pontificia Universidad Católica de Chile. Facultad de Medicina, Departamento de Salud Pública $(J C, J)$ Departamento de Enfermedades Infecciosas e Inmunología Pediátrica (KA)

Comité Consultivo de Inmunizaciones. Sociedad Chilena de Infectología (JC)

Sin conflicto de interés para esta vacuna $(J C, K A, J J)$ Fuente de financiamiento: no hubo.

Recibido: 6 de abril de 2015

Correspondencia a: Jaime Cerda Lorca jcerda@med.puc.cl

\section{Measles outbreaks in developed countries. A lesson for Chile}

The measles vaccine has been used for over 50 years and has proven to be safe, effective and inexpensive. Nevertheless, in 2013 145,700 measles deaths occurred, mostly in countries with low per capita income and weak health infrastructure. The occurrence of measles cases is not restricted to developing countries, but also affects developed countries (Europe and USA), where is associated with a reduction in vaccination coverage, explained by a loss of confidence of some parents in the vaccine. This perspective article addresses the loss of confidence in the vaccine, and the individual and collective consequences of the decision to not vaccinate a child. Various strategies to reverse this phenomenon are presented, most notably the continuing education of health professionals, parents and patients using scientific arguments, given in an understandable and interesting language. Finally, the current situation of Chile (a country with current certification of measles elimination) is presented, emphasizing the importance of maintaining this condition.

Key words: Measles, vaccines, epidemics.

Palabras clave: Sarampión, vacunas, epidemia. uenta la historia que Rhazes, médico persa del siglo X, fue el primero en identificar el sarampión como una entidad nosológica distinta a la viruela, dejando evidencia escrita de ello (De variolis et morbillis, o Tratado sobre la Viruela y el Sarampión) ${ }^{1}$. Siglos después, el primer hospital infantil en Chile fue fundado a raíz de una epidemia de sarampión que asoló el país entre 1899-1900 y que, según estimaciones de la época, habría afectado a 60 mil niños, falleciendo no menos de $10 \mathrm{mil}^{2}$. La desigual lucha entre el ser humano y el virus del sarampión comenzó a cambiar recién en la segunda mitad del siglo XX, con el advenimiento de la vacuna contra este virus. La vacuna ha sido utilizada por más de 50 años y ha demostrado ser segura, efectiva y de bajo costo (1 dólar por niño). En 2013, cerca de $84 \%$ de los niños del planeta habían recibido una dosis de esta vacuna al año de vida, y se estima que durante el período 2000-2013 la vacunación previno 15,6 millones de muertes, equivalente a una reducción de $75 \%$ en el número de fallecidos. No obstante ello, en el año 2013 ocurrieron 145.700 muertes por sarampión, es decir, casi 400 muertes diarias, o 16 muertes por hora. Más de 95\% de estas muertes ocurrieron en países de bajo ingreso per cápita e infraestructura sanitaria débil, demostrando que la lucha contra el sarampión está lejos de haber concluido ${ }^{3}$.

La ocurrencia de casos de sarampión no se restringe a países en vías de desarrollo, sino que también afecta a países desarrollados. En Estados Unidos de América (E.U.A.), entre el 1 de enero y 27 de febrero de 2015 se reportaron 170 casos en 17 Estados y el Distrito de Columbia. Un $74 \%$ de los casos forma parte de un gran brote multiestatal, siendo la mayoría de los afectados no-vacunados. Los casos de sarampión reportados en E.U.A. presentaron en 2014 una cifra récord: 644 casos en 27 Estados, el mayor número de casos reportado desde que se documentara en 2000 la eliminación del sarampión en dicho país ${ }^{4}$. Por su parte, en 30 países de la Unión Europea/Área Económica Europea el panorama es igualmente desalentador, habiéndose reportado durante 2014 un total de 3.616 casos, de los cuales $46,3 \%$ ocurrieron en Italia y $12,3 \%$ en Alemania. Del total de casos con información sobre antecedente de vacunación, $83 \%$ correspondieron a no-vacunados, cifra que alcanzó a 75\% en los niños de 1-4 años. Es importante destacar que el número de casos se redujo respecto a 2013 (10.537 casos), 2012 (11.316 casos), 2011 (32.033 casos) y 2010 (32.480 casos), hecho posiblemente atribuible a una reducción de la población susceptible producto de las epidemias ocurridas en los años precedentes. No obstante ello, el número de casos registrados en 2014 es alto, en especial si se considera que se esperaba la eliminación del sarampión en Europa para 2015 5 .

¿Cómo se explica que en pleno siglo XXI países del primer mundo presenten brotes de sarampión, existiendo una vacuna utilizada por más de 50 años y que ha demostrado ser segura, efectiva y de bajo costo? La respuesta parece estar dada por una reducción en la cobertura de vacunación contra el sarampión, pues se sabe que se requiere de una cobertura de al menos $95 \%$ con dos dosis de la vacuna para interrumpir la transmisión viral. En 2013, 22 países de la Unión Europea/Área Económica Europea presentaron cobertura de vacunación bajo dicho umbral, además de existir "bolsillos" de sujetos susceptibles incluso en países con alta cobertura ${ }^{5,6}$. La reducción de la cobertura de vacunación contra el sarampión nos conduce 
a una segunda pregunta, de más difícil respuesta: ¿Por qué algunos padres y madres deciden no vacunar a sus hijos, manifestando así su desconfianza hacia a las vacunas? Los episodios de desencuentro entre quienes confían en las vacunas y quienes desconfían de ellas no son nuevos, remontándose al advenimiento de la vacuna antivariólica, a comienzos del siglo XIX $\mathrm{XI}^{7}$. Posiblemente la construcción de la confianza entre la vacunación y la sociedad haya tenido una época dorada, comprendida entre las décadas de 1940 y 1980. Para aquel entonces existía una altísima valoración de las vacunas, percibidas por la sociedad como herramientas efectivas y seguras para reducir la morbilidad y mortalidad ocasionada por continuos brotes de enfermedades infecciosas, cuyos efectos deletéreos eran parte de la vida diaria. Difícilmente una familia de la época no contaba con algún familiar o conocido muerto o secuelado a consecuencia de alguna de las frecuentes epidemias (ej. viruela, sarampión, poliomielitis y difteria, entre otras) que solían declararse, las cuales afectaban preferentemente a la población infantil. Con el transcurso del tiempo, al producirse una marcada reducción en la ocurrencia de epidemias y su consiguiente amenaza sobre la salud e integridad de individuos y familias, la sociedad fue adoptando progresivamente una postura más complaciente sobre los riesgos asociados a las enfermedades infecciosas ("cosas del pasado"), desplazando su objeto de atención hacia los efectos adversos supuestamente producidos por las vacunas ("cosas del presente").

Gostin, en un artículo publicado con motivo del reciente brote de sarampión en E.U.A., señala que éste reavivó una polémica histórica sobre los valores de la salud pública, la elección personal, y los derechos de los padres ${ }^{8}$. Resurgen entonces las siguientes preguntas: ¿Deben los padres y madres ejercer de manera autónoma el derecho de cuidar a sus hijos de la manera que consideren adecuada? ¿Es válida la decisión parental de no vacunar a un niño, omisión que potencialmente pone en riesgo a la comunidad, en especial a quienes por razones médicas no pueden vacunarse, $\mathrm{y}$ dependen de la inmunidad de rebaño? ¿Es justo que los niños no-vacunados eviten los poco frecuentes efectos adversos asociados a la vacuna y, sin embargo, se beneficien de la inmunidad de rebaño que le construyen los demás? En la actualidad, la pérdida de confianza en las vacunas se concentra en ciertos grupos específicos de la sociedad, por ejemplo, los padres y madres de niños afectados por ciertas condiciones neurológicas de carácter crónico y de etiología desconocida. En su legítimo anhelo por conocer la causa de la condición de sus hijos, y con la esperanza de poder ofrecerles alguna terapia, algunos padres y madres apoyan la existencia de una asociación de tipo causal entre la administración de una determinada vacuna y el desarrollo de la condición neurológica. Lamentablemente, sus argumentos parecen ser más cercanos a la emocionalidad que a la evidencia científica disponible. Y es precisamente en estos angustiados padres y madres donde encuentran terreno fértil ciertas hipótesis infundadas, o lisa y llanamente fraudulentas, como fue el planteamiento hacia fines de la década de 1990 de una asociación entre la vacuna tresvírica y el desarrollo de autismo 9 . Dichos padres y madres sufren por partida doble, pues al dolor que significa sobrellevar la condición de sus hijos se suma aquel producido por quien sigue pistas falsas ${ }^{10}$, las cuales en algunos casos pueden motivar acciones de consecuencias nefastas (ej. quelación de metales en niños autistas).

En todo ámbito de cosas resulta mucho más fácil destruir confianzas que construirlas $\mathrm{y}$, por cierto, los fracasos resultan ser más mediáticos que los aciertos. El caso Wakefield ${ }^{9}$ es un claro ejemplo del alto costo que tuvo el destruir sin fundamentos la confianza que durante años se había logrado construir en Inglaterra entre los padres y madres y la vacunación tresvírica: la cobertura de vacunación tresvírica cayó desde 91\% (1998) a por debajo de $80 \%$ (2003), y los casos aumentaron desde 56 (1998) a 1.370 (2008), reemergiendo una enfermedad previamente controlada y su secuela de hospitalizaciones, pérdidas de días de colegio y trabajo, y muertes ${ }^{9}$. Ahora bien, una mirada responsable sobre el tema obliga a no adoptar posiciones extremas, y reconocer que la administración de vacunas no está exenta de riesgos (al igual que la administración de cualquier producto biológico). Y en el caso de la administración de una vacuna, este riesgo se hace realidad en un sujeto previamente sano, hecho que le otorga una connotación especial. El desafío actual es, en consecuencia, lograr restaurar y fortalecer la confianza depositada por cientos de padres y madres en esta valiosa herramienta preventiva, teniendo en cuenta sus fortalezas y debilidades. ¿Cómo lograrlo? Poland propone algunas ideas, destacando el financiamiento y publicación de estudios de alta calidad que aborden las preocupaciones relacionadas a la seguridad de las vacunas, mantener y mejorar programas de vigilancia de eventos adversos asociados a la administración de vacunas, implementar programas de compensación por lesiones causadas por vacunas, y educar a los profesionales de la salud, padres y pacientes utilizando argumentos científicos, impartidos en un lenguaje comprensible, de modo que logren hacer un correcto balance entre los riesgos y beneficios tanto individuales como poblacionales que implica el no vacunar a un niño, así como lograr que dispongan de herramientas que les permitan no hacer eco a rumores sin fundamentos científicos ${ }^{11}$. Por su parte, Offit profundiza sobre la forma en que la evidencia científica debe ser transmitida al público, sugiriendo que ésta sea informativa e interesante para los medios de comunicación, así como explicar los métodos utilizados por científicos y clínicos para distinguir entre relaciones causales versus meras coincidencias. Más aún, señala que los profesionales de la salud pueden ayudar a los padres a comprender la relación entre las vacunas y enfermedades específicas explicándoles que pese a que reportes de casos pueden ser usados para formular hipótesis, solamente los estudios cuidadosamente diseñados y bien controlados pueden ser utilizados para verificarlas ${ }^{12}$. 
Con gran satisfacción podemos decir que la situación actual de nuestro país contrasta con la descrita en E.U.A. y Europa. En Chile, la vacunación contra el sarampión se realiza desde 1964, siendo administrada a los niños de 12 meses, con revacunación durante el primer año de enseñanza básica. Desde 1992 se desarrolla cada 4 años una campaña de vacunación para eliminar cohortes que puedan presentar susceptibilidad al sarampión. La documentación para la certificación de la eliminación de sarampión en Chile fue elevada en $2011^{13}$, siendo aprobada por la Organización Panamericana de la Salud. Desde hace varios años no se registran casos autóctonos de sarampión en nuestro país, ya que su transmisión endémica se interrumpió en 1992. Sin embargo, la amenaza de una reemergencia del sarampión está siempre latente. Por un lado, la globalización y sus constantes movimientos de personas por el mundo continúan generando casos asociados a importación (los últimos registrados en Chile ocurrieron en 2011 y fueron 6 casos), los cuales tienen la potencialidad de producir un brote en el caso de encontrar un grupo de sujetos susceptibles ${ }^{14}$. Por otro lado, la cobertura a nivel nacional de vacunación tresvírica (primera dosis, 12 meses de edad) durante el período 2005-2012 tuvo un rango entre 87,5 y $93,5 \%$ (con importantes variaciones regionales) ${ }^{15}$, lo cual significa que cada año se acumula una cifra considerable de susceptibles, a la que se debe sumar los niños vacunados que no desarrollaron inmunidad post-vacuna. Por tal razón, es de suma importancia que los profesionales de la salud apoyemos a la Campaña de Vacunación 2015, la cual permitirá poner al día la inmunidad de miles de personas en nuestro país.

Esperamos que Chile mantenga su senda de éxito, y que aprendamos la lección que nos están brindando países desarrollados. Para ello, una premisa fundamental es nunca bajar la guardia y mantenernos siempre alerta ante una posible reemergencia de esta enfermedad. Asimismo, entender (y saber explicar) que la decisión autónoma de aquellos padres y madres de no vacunar a sus hijos no tiene fundamentos científicos que la avale, es riesgosa para sus propios hijos y es perjudicial para toda la sociedad, especialmente para aquellos que dependen de la inmunidad de rebaño que le brindamos los demás. Sean entonces bienvenidos todos los esfuerzos desplegados para fortalecer la confianza que nuestra sociedad ha depositado en la vacuna tresvírica.

\section{Resumen}

La vacuna contra el sarampión ha sido utilizada por más de 50 años y ha demostrado ser segura, efectiva y de bajo costo. No obstante ello, en 2013 ocurrieron 145.700 muertes por sarampión, mayoritariamente en países de bajo ingreso per cápita e infraestructura sanitaria débil. La ocurrencia de casos de sarampión no se restringe a países en vías de desarrollo, sino que también afecta a países desarrollados (Europa y Estados Unidos de América), lugares donde se asocia a una reducción en la cobertura de vacunación, explicada por una pérdida de confianza por parte de algunos padres y madres en la vacuna. El presente punto de vista aborda el tema de la desconfianza hacia la vacuna y las consecuencias tanto individuales como poblacionales que tiene la decisión de no vacunar a un niño. Se presentan distintas estrategias para revertir este fenómeno, entre las que destaca la educación permanente de profesionales de la salud, padres y pacientes utilizando argumentos científicos, impartidos en un lenguaje comprensible e interesante. Por último, se presenta la situación actual de Chile (país con certificación vigente de eliminación del sarampión), enfatizando la importancia de mantener dicha condición.

\section{Referencias bibliográficas}

1.- Modanlou H. A tribute to Zakariya Razi (865-925 AD), an Iranian pioneer scholar. Arch Iranian Med 2008; 11: 673-7.

2.- Laval E. La epidemia de sarampión de 18991900 en Chile y la creación del primer hospital de niños de Santiago. Rev Chilena Infectol 2002; 19: 121-3.

3.- World Health Organization. Fact Sheet $N^{\circ} 286$ : Measles (Reviewed February 2015. Disponible en: http://www.who.int/mediacentre/factsheets/ fs286/en/ (Consultado el 03 de marzo de 2015).

4.- Centers for Disease Control and Prevention. Measles cases and outbreak. Disponible en: http://www.cdc.gov/measles/cases-outbreaks html (Consultado el 03 de marzo de 2015).

5.- European Centre for Disease Prevention and Control. Measles and rubella monitoring, January 2015-Reporting on January to December 2014 surveillance data and epidemic intelligence data to the end of January 2015. Disponible en: http://www.ecdc.europa.eu/
en/publications/Publications/Measles-rubellamonitoring-first-quarter-2015.pdf (Consultado el 03 de marzo de 2015).

6.- Global Health Observatory Data Repository. Measles (MCV) Data by country. Disponible en: http://apps.who.int/gho/data/view. main.80100?lang=en (Consultado el 03 de marzo de 2015).

7.- Wolfe R M, Sharp L K. Anti-vaccionationists past and present. Br Med J 2002; 325: 430-2.

8.- Gostin L O. Law, ethics, and public health in the vaccination debates: politics of the measles outbreak. JAMA 2015; 313: 1099-100.

9.- Flaherty D. The vaccine-autism connection: a public health crisis caused by unethical medical practices and fraudulent science. Ann Pharmacother 2011; 45: 1302-4.

10.- Taylor L E, Swerdfeger A L, Eslick G D. Vaccines are not associated with autism: an evidence-based meta-analysis of case-control and cohort studies. Vaccine 2014; 32: 3623-9.

11.- Poland G, Jacobson R. The age-old struggle against the antivaccinationist. New Engl J Med 2011; 364: 97-9.

12.- Offit $\mathrm{P}$, Coffin S. Communicating science to the public: MMR vaccine and autism. Vaccine 2003; 22: 1-6.

13.- Departamento de Epidemiología, Ministerio de Salud. Documentación para la verificación de la eliminación de sarampión, rubéola y síndrome de rubéola congénita en Chile (2011). Disponible en: http://epi.minsal. cl/epi/html/bolets/reportes/Sarampion/ ElimSarampionOPS.pdf (Consultado el 9 de marzo de 2015).

14.- Departamento de Epidemiología, Ministerio de Salud. Vigilancia Integrada Sarampión-Rubéola. Situación epidemiológica, enero-junio de 2014. Boletín Epidemiológico Trimestral, Volumen 110, Número 2, Año 2014.

15.- Departamento de Estadísticas e Información de Salud. Cobertura de Inmunizaciones Programáticas 2005-2012. Disponible en: http:// www.deis.cl (Consultado el 25 de marzo de 2015). 